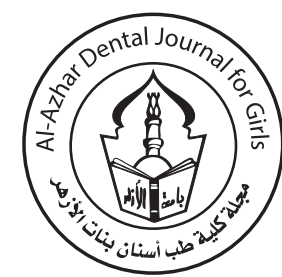

\title{
Evaluation of Different Attachment Systems on Single Implant Retained Mandibular Overdenture
}

\author{
Sara Medhat ${ }^{1}$, Nesrin A El-Mahrouky ${ }^{2}$, Hala M Gamal El-Din ${ }^{3}$, Nahed A. Abd El Moniem ${ }^{4}$
}

Codex : 20/1904

azhardentj@azhar.edu.eg

http://adjg.journals.ekb.eg

DOI: 10.21608 /adjg.2019.5790.1021

\section{KEYWORDS}

Implant ,

Ball and socket,

Equator.

\begin{abstract}
Purpose: This study was conducted to evaluate bone height around ball and socket and equator attachment in mandibular overdenture retained by single implant. Material and methods: Ten completely edentulous patients were selected with ages ranging from 50-60 years. Single implant was inserted for each patient and they all received heat cured acrylic dentures. The ten patients were divided into two groups, group (I) have received ball \&socket attachment, group (II) received equator attachment. In the fitting surface of the lower denture two holes where made between 6 and 7 acrylic teeth and were filled with radioopaque material (amalgam). These represented posterior marker areas of evaluation the bone height. Evaluation of bone height around the implant and the posterior edentulous area which were marked for measurement was done by CAD_CAM CT at the time of attachment placement then after 3 months then 6 months. Results: In our study the comparison of equator and ball and socket attachments regarding the bone height changes around the implant revealed a significant difference. On the other hand there was an insignificant difference when comparing the distal extension area between them throughout the six months studies period. Conclusion: According to this study the equator attachment group indicates lesser marginal bone loss, as compared with the ball and socket attachment group, and there is no difference in bone resorption on the posterior area of the ridge between the two attachments.
\end{abstract}

\section{INTRODUCTION}

Despite adequate denture fabrication, edentulous patient with resorbed mandible represents a significant health care problem . It is not possible to achieve optimal retention and stability in the conventional mandibular denture. Overdenture help to partly overcome many problem

- Paper extracted from Master thesis titled "Evaluation of Different Attachment Systems on Single Implant Retained Mandibular Overdenture"

1. Dentist in Ministry of Defense

2. Head and Professor of Removable Prosthodontic Department, Faculty of Dental Medicine for Girls, Al-Azhar University.

3. Professor of Removable Prosthodontic Department, Faculty of Dental Medicine for Girls, Al-Azhar University.

4. Lecturer of oral surgery and Maxillofacial Surgery Department, Faculty of Dental Medicine for Girls, Al-Azhar University. 
related to conventional complete denture like progressive bone loss, poor stability and retention, and low masticatory efficiency. Oral functions improve significantly after using mandibular implant overdenture. Most studies on implant treatment and oral function showed a significant improvement of the objective masticatory performance in the mandible ${ }^{(1)}$.

Single implant retained overdenture is less expensive and less surgical invasive than multiple implants. Midline implant placement allows for simplified imaging and flap design, without concurrence for the position of the mental foramen or possible postoperative paresthesia related to direct or indirect damage to branches of the posterior alveolar nerve ${ }^{(2,3)}$.

There are numbers of different attachments that can be used to secure a mandibular denture to dental implants including The ball attachment retained over denture provides a more simplified approach to stabilizing mandibular denture. It is a simple attachment due to the shape of the male unit which is soldered to the dowel coping, while female part is embedded within acrylic resin of the prosthesis. Retention is obtained by frictional fit of female on male in snap like action between both parts when the overdenture is inserted ${ }^{(4,5)}$.

Equators feature a titanium nitride (TiN) coating for maximum resistance to wear, a small-scale metal housing and replaceable nylon caps suitable for various retention levels that can be replaced easily within seconds. Retention caps are made of highly resilient and flexible materials allowing for movement of up to 8 degrees from the axis of the abutment without misalignment or retention loss. Equators improve esthetics and reduce residual ridge resorption, with as few as two to four implants; reducing both the trauma and high cost associated with placing more implants ${ }^{(6)}$.

In spite of several studies of ball and socket and equator. Our study will be conducted to show the effect of ball and socket and equator on bone height around the single implant retained mandibular over denture and the distal extension area.

\section{MATERIAL AND METHODS}

Ten completely edentulous patients were selected. Patients' ages ranged from 50-60 years. All Patients had well developed lower ridges without any undercuts exostosis or tori. All patients were free from neuromuscular and tempro-mandibular joint disorders and healthy mucosa free from any ulceration, inflammation or infections. At least 6 months were elapsed after last extraction. Patients were free from any systemic disease that may interfere with dental implant placement and/or osseointegration.

All patients accepted this dental treatment and were informed about the steps of this study and signed a written consent with the Research Ethics Committee (REC) approval. Patient history and clinical examination for medical, dental, extra oral, intra oral, laboratory investigation and radiographic examination were carried out for each patient. Diagnostic cast was carried out and radiographic stent to made Cone beam CT to evaluation the bone height, width and quality at the implant proposed site.

Ten patients received heat cured acrylic resin complete denture. Surgical procedures were carried out to put single implant in mid line with flapless technique. The implant used in this study for all patients had a length of $11.5 \mathrm{~mm}$ and its diameter 3.2 to be standardized in all cases. Three months following the surgery after complete osseointegration, implant sites were marked using the surgical stent and a punch was used to expose the covering screw which was removed. Then the patients were divided into 2 group's .Five patients in each group. Group (I) received ball and socket attachment and group (II) received equator attachment. After checking the occlusion and absence of rocking, pick up procedure started by blocking the space around the ball under the metal housing by dental floss to facilitate pick up procedure and to prevent the self-cure acrylic resin lock in the undercut. 
Cold cure acrylic resin was placed into relieved area of the denture and the denture was seated in the patient's mouth. Patient closed in centric occlusion until the acrylic resin polymerized. The lower denture was removed with ball housing which was picked up in the fitting surface. Lower denture was finished and polished. In the fitting surface of the lower denture two holes between 6 and 7 acrylic teeth were made and filled with radioopaque material (amalgam) these represented posterior marker areas for evaluation the bone height.

Evaluation of bone height around the implant and the posterior edentulous area which were marked for measurement was done by CAD_CAM $\mathrm{CT}$ at the time of attachment placement then after 3 months then 6 month.

The mean of the crestal bone loss around the implant was calculated by measuring bone height mesial, distal, buccal and lingual surfaces and divided by four to give the mean of bone height of each patient.

\section{STATISTICAL ANALYSIS}

All measurements were recorded and tabulated. Statistical analysis of the data was performed with SPSS 25 ( Statical package for Scientific Studies) for Windows.Data analysis was performed, one-way analysis of variance independent $t$ - test was used for comparing means and standard deviationvalues of two different types of attachment .The significance level was set at P- value less than 0.05 .

\section{RESULTS}

\section{Bone height change around both attachments from 0 to 3 months, 3 to 6 months}

At insertion time, after three months and after six months, the overall bone loss around the implant in anterior region between two groups was statistically significant difference ( $\mathrm{P}$-value $<0.05$ ), as showed in (figure 1,2).

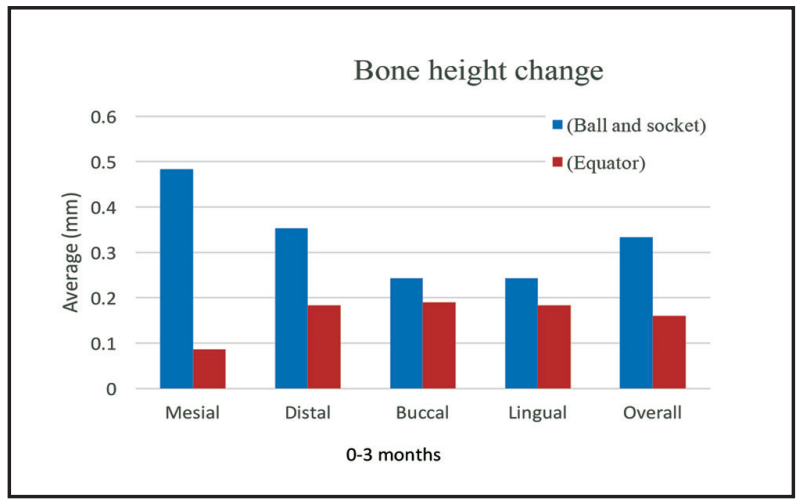

Figure (1): Bar chart showing average bone height change from 0 to 3 months in the anterior region

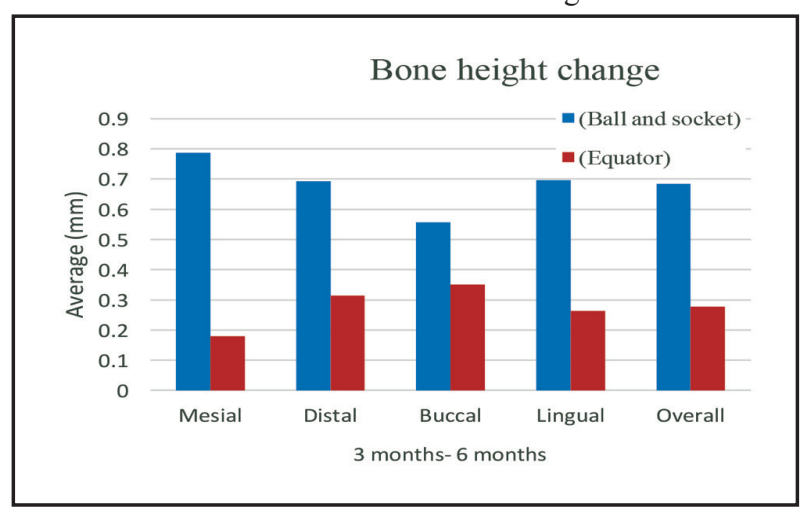

Figure (2): Bar chart showing average bone height change around both attachments from 3 to 6 months

\section{Posterior bone height change:}

At insertion time, after three months and after six months the overall bone loss around the implant in posterior region between two groups was statistically insignificant difference ( P-value > 0.05 ), as showed in (figure 3,4).

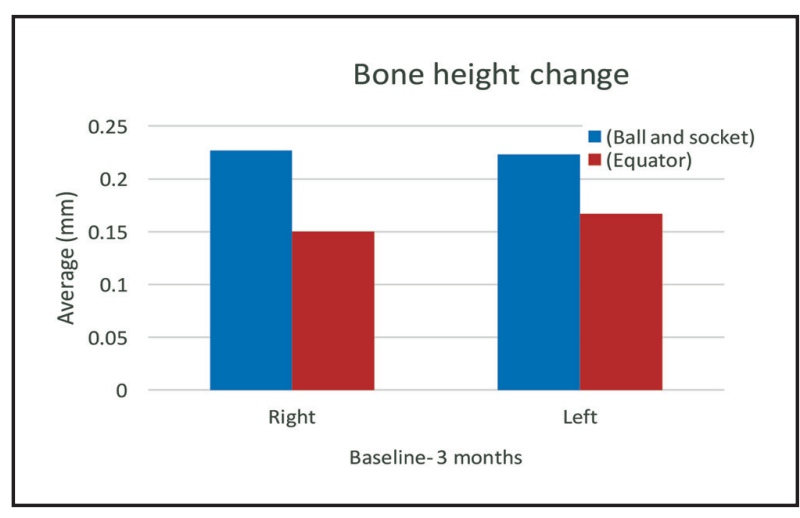

Figure (3): Bar chart showing average bone height change from 0 to 3 months in the posterior region 


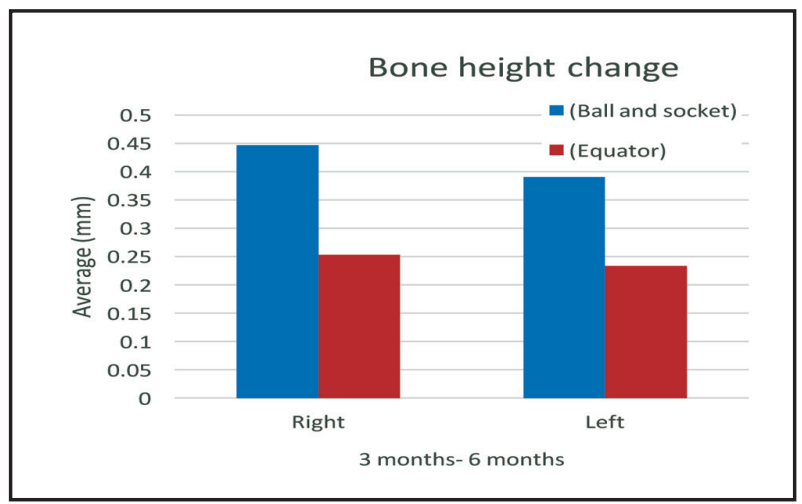

Figure (4): Bar chart showing average bone height change when using both attachments from 3 to 6 months in the posterior region

\section{DISCUSSION}

In this study the comparison of equator and ball attachments regarding the bone height changes around the implant revealed a significant difference. On the other hand there was an insignificant difference when comparing the distal extension area between them throughout the six months studies period.

This may be due to that the equator is low profile resilient attachment performance which is superior to that of the ball and socket attachment in the implant. This resiliency of the equator permits denture movement in every direction and distribution of stress induce lower stress on bone around implant ${ }^{(7)}$.

The equator is coated with titanium nitride (TiN) coating which provides maximum resistance to wear, also a small-scale metal housing and replaceable nylon caps, offer various retention levels. Retention caps can be replaced easily within seconds. This form of attachment has the minimum vertical height and diameter for the overdenture abutment available in the market with $1.7 \mathrm{~mm}$ height and 2.5 $\mathrm{mm}$ diameter which lead to low stress on the bone around implant ${ }^{(8)}$.

The results also comes in agreement with previous studies that showed that the decrease marginal bone loss around the implant in crestal region which was usually a significant indicator of implant health ${ }^{(9)}$. Dental implants were subjected to initial remodeling around the coronal part of the implant during the first six months. The greater bone loss occurs related to maturation and adaption of bone after surgery to withstand functional forces ${ }^{(10,11)}$.

This study showed that the accumulated mean of marginal bone loss recorded after 6 months to be $0.475 \mathrm{~mm}$ around the equator attachment which is in agreement with many previous studies that recorded a bone loss of $0.74 \pm 0.20 \mathrm{~mm}$ after 6 months ${ }^{(12)}$,also another study recorded a mean bone loss of 0.5531 $\mathrm{mm}^{(10)}$ and also study concluded that the mean bone loss was $0.60 \mathrm{~mm}$ at 6 months ${ }^{(13)}$. This may be attributed to the low profile and small dimensions of the equator attachment that decrease stresses transferred to the crestal bone area causing less bone resorption. This explanation is in agreement with study concluded that low profile design played a role in dissipating occlusal loads through the abutment to the implant ${ }^{(14)}$,also concluded that the small diameter attachment is the better attachments to be used for implant supported-overdenture in terms of minimizing the stresses to the bone ${ }^{(11)}$.

Our findings are also in agreement with another study concluded that resilient implant attachments reduced strains around the implant site so that less bone resorption around the implant takes place ${ }^{(15)}$.

On the other hand a previous study reported that the resilient attachment allows for more movements of the denture base. Therefore, more stresses will be applied on bone around the implant ${ }^{(16)}$. Furthermore, it was reported that the ball attachment provides better retention and better resistance to wear on the long term in comparison to resilient attachments. If the Wear and retention are low, this allow more movement of the denture base which will direct more forces towards the bone and eventually more resorption ${ }^{(17)}$.

In this study there was insignificant difference when comparing ball and socket and equator in 
distal extension area which is in agreement with the results of photoelastic stress analysis which concluded ,that load transmitted to the implant was equally distributed over the posterior two sides of single implant retained mandible overdenture, when using different attachments, with low stress concentration on the bone ${ }^{(18)}$.

In another study of finite element analysis (FEA) under vertical load on molar region with different attachment found that the single implant overdenture tend to rotate over the implant with no strain concentration observed ${ }^{(19)}$.

From biomechanical point of view during mastication ,the occlusal forces on the posterior teeth of the single implant retained mandibular over denture made the denture move freely in all directions and effective stress concentration around the crestal bone was reduced ${ }^{(20)}$.

\section{CONCLUSION}

According to this study the equator attachment group indicates lesser marginal bone loss, as compared with the ball and socket attachment group, and there is no difference in bone resorption on the posterior area of the ridge between the two attachments.

\section{REFERENCES}

1. Van Kampen FM, Van Der Bilt A, Cune MS, FontijnTekamp FA, Bosman F. Masticatory function with implantsupported overdentures. J Dent Res 2004;83:708-11.

2. Cheng T, Ma LI, Liu XL, Sun GF, He XJ, Huo JY, Et al. Use of a single implant to retain mandibular overdenture .A preliminary clinical trial of 13 cases, J Dent Sci 2012;7:261-6.

3. Barai GD, Jaju SB, Tidke DJ , Rathi NH. Review article FEM analysis of single implant retained mandibular overdenture with four different attachment types: A review. Int Health Biomed Res 2016;4:29-34.

4. Cune M, Burgers M, van Kampen F, de Putter C, van der Bilt A. Mandibular overdentures retained by two implants: 10-year results from a crossover clinical trial comparing ball socket and bar-clip attachments. J Int Prosthodont $2010 ; 23: 310-7$.

5. Cune M, Van Kampen F, Van der Bilt A, Bosman F. Patient satisfaction and preference with magnet, bar-clip, and ballsocket retained mandibular implant overdentures: a crossover clinical trial. J Prosthet Dent 2005;94:471.

6. Marcello $\square$ Machado RM, Faot F, Schuster AJ, Bielemann AM, Chagas Júnior OL, Del Bel Cury AA. One year clinical outcomes of locking taper Equator attahments retaining mandibular overdentures to narrow diameter implants. Clin Impl Dent Rel Res 2018;20:483-92.

7. Amiri EM, Atri F, Khalilpour M, Alhavaz SB. Comparing the Effect of Different Inter-Implant Distances on the Retention of Locator and Ball Attachments . J Int Adv Bio \&Res 2017 ;8:46-58.

8. Mínguez-Tomás N, Alonso-Pérez-Barquero J, FernándezEstevan L, Vicente-Escuder Á, Selva-Otaolaurruchi EJ. In vitro retention capacity of two overdenture attachment systems: Locator and Equator. J Clin and Experi Dent $2018 ; 10: 681$.

9. Shady MM, Eltorky IR, Eaal ZM. Comparative study of two types of attachments for mandibular implant-retained single complete overdenture. J Tanta Dent 2016; 13: 157-61.

10. Nandal S, Ghalaut P, Shekhawat H. A radiological evaluation of marginal bone around dental implants: An in-vivo study. J National Maxillofac Surg 2014; 5:126.

11. John J, Rangarajan V, Savadi RC, Kumar KS, Kumar PS. A Finite Element Analysis of Stress Distribution in the Bone, Around the Implant Supporting a Mandibular Overdenture with Ball/O Ring and Magnetic Attachment. J Indian Prosthodont Soc 2012;12 : 37-44.

12. Fernández AF, Mahmud FJ, Carrió CP, Oltra DP, Conejero J, Diago MP. Radiological assessment of peri-implant bone loss: a 12-month retrospective study.J Clin and Experi Dent 2011; 3: 430-4.

13. Kamburoğlu K, Gülşahı A, Genç Y, Paksoy CS. A comparison of peripheral marginal bone loss at dental implants measured with conventional intraoral film and digitized radiographs. J Oral Impl 2012;38:211-9.

14. Abdelhamid AM, Assaad NK, Neena AF. Three Dimensional Finite Element Analysis to Evaluate Stress Distribution around Implant Retained Mandibular Overdenture Using Two Different Attachment Systems. J Dent Health Oral Disord Ther 2015;2:65. 
15. Doundoulakis JH, Eckert SE, Lindquist CC, Jeffcoat MK. The implant-supported overdenture as an alternative to the complete mandibular denture. J Amer Dent Assoc 2003; 134:1455-8.

16. Elsyad MA, Omran AO, Fouad MM .Strains Around Abutment Teeth with Different Attachments Used for Implant-Assisted Distal Extension Partial Overdentures: An In Vitro Study". J Prosthodont 2017;26: 42-7.

17. Wolf K, Ludwig K, Hartfil H, Kern M. Analysis of retention and wear of ball attachments. Quintessence Int 2009;40: 405-12.
18. Nascimento JF, Aguiar Júnior FA, Nogueira TE, Rodrigues RC, Leles CR.Photoelastic Stress Distribution Produced by Different Retention System for a Single implant Mandibular Overdenture. J Prosthet 2015;24:538-42.

19. Liu J, Pan S, Dong J, Mo Z, Fan Y, Feng H. Influence of implant number on the biomechanical behavior of mandibular implant-retained/supported overdentures: a three-dimensional finite element analysis. J Dent 2013; 41:241-9.

20. 20-Maeda Y, Horisaka M, Yagi K. Biomechanical rationale for a single implant retained mandibular overdenture: an in vitro study. Clin Oral Impl Res 2008;19:271-5. 